\title{
Aprendendo sobre Trabalho Escravo no Brasil por meio da criação de um Jogo Digital Educativo
}

\section{Learning about Slave Labor in Brazil through the cre- ation of an Educational Digital Game}

\section{JADERSON JASON BARBOSA AGUIAR}

Universidade Federal de Campina Grande

\begin{abstract}
Resumo: Neste artigo, é relatada uma experiência vivenciada em relação à definição e ao desenvolvimento de um jogo digital educativo voltado ao tratamento, em ambientes educacionais, do tema Trabalho Escravo. Esta experiência destaca-se por incentivar o processo de ensino e aprendizagem desse tema em dois momentos: (i) durante o desenvolvimento do jogo, dado que o grupo de desenvolvimento foi composto por alunos em ambiente escolar; e (ii) após a conclusão das versões do jogo, apresentadas a discentes e docentes avaliadores. Neste artigo, são descritos o processo e resultados da elaboração do jogo, ressaltando-se tanto o uso quanto a aplicação de Tecnologias Digitais da Informação e da Comunicação no espaço escolar. Em relação aos resultados dessa experiência, destaca-se o conceito Ótimo atribuído ao grupo de alunos/desenvolvedores, em dois momentos de avaliação formal, além do visível interesse desses alunos em estudarem o tema Trabalho Escravo e os conteúdos técnicos para o desenvolvimento do jogo.
\end{abstract}

Palavras-chave: Jogo digital educativo. Trabalho escravo. Jogos desenvolvidos por estudantes. Experiência de ensino e aprendizagem. Aprendizagem baseada em jogos digitais.

\begin{abstract}
This paper reports an experience regarding the definition and development of a digital educational game aimed at the study of the theme of Slave Labor in educational environments. This experience stands out by promoting the teaching and learning process of this theme in two instances: (i) during the development of the game, given that the development group was composed of students in the school environment; and (ii) after the conclusion of the versions of the game, which were presented to students and teachers/evaluators. This paper describes the process and results of the game development, emphasizing the use and application of Digital Information and Communication Technologies in school education. It is important to highlight the $A$ concept attributed to students/developers in two moments of formal evaluation, besides the apparent interest of these students in studying the theme Slave Labor and the technical content for the development of the game.
\end{abstract}

Keywords: Educational digital game. Slave Labor. Games developed by students. Teaching and learning experience. Digital game-based learning. 


\title{
1 Introdução
}

Embora, por muito tempo, se tenha confundido o termo "ensinar" com o termo "transmitir", tratando o professor como transmissor e o aluno como agente passivo da aprendizagem (REIS et al., 2008), as Tecnologias Digitais de Informação e Comunicação (TDIC) têm entusiasmado crianças, jovens e adultos a buscarem todo tipo de informação, sendo a utilização de jogos digitais uma das maneiras com que a tecnologia tem chegado à sala de aula, aperfeiçoando o perfil dos nativos digitais nesse ambiente (DA SILVA NETO et al., 2013; OLIVEIRA et al., 2017).

Desde os mais simples, com perguntas e respostas, aos mais ricos e complexos, com um mundo imaginário, os jogos educativos se destacam como ferramentas de aprendizagem por propor estímulo ao interesse do aluno, ajudando-o a estabelecer novas descobertas, desenvolvendo sua personalidade, além de simbolizar um instrumento pedagógico para o professor conduzir, estimular e avaliar a aprendizagem (REIS et al., 2008).

Costa et al. (2006) afirmam que os jogos educativos devem oferecer um ambiente crítico, possibilitando ao aprendiz sensibilizar-se na construção de seu conhecimento com oportunidades prazerosas para o desenvolvimento de suas habilidades cognitivas. Além disso, De Azevedo et al. (2011) defendem que esse tipo de jogo pode servir para conscientizar e politizar questões sociais relevantes, potencializando e criando condições favoráveis a um aprendizado mais envolvente e significativo.

É possível considerar os jogos como instrumentos facilitadores de aprendizagem significativa dos alunos, tomando Piaget, Vygotsky e Ausubel como aporte teórico:

\begin{abstract}
De acordo com Piaget (1971), o brincar reflete o nível de desenvolvimento cognitivo da criança por meio dos processos de assimilação e acomodação e tem a função de possibilitar a execução e consolidação das habilidades adquiridas. Nessa perspectiva, os jogos educativos podem facilitar o processo de ensinoaprendizagem, como instrumento metodológico prazeroso, interessante e desafiante, tornando-se um rico recurso para a construção do conhecimento. [...] Vygotsky (2003) coloca que o homem é um ser sócio-histórico, ou seja, o homem se estabelece através das relações e contradições do meio. Nesse sentido, o jogo poderá possibilitar a construção do conhecimento do educando, servindo como mediador entre conteúdo disciplinar e a realidade histórico-social do educando. [...] Por meio do jogo o aprendiz desenvolve a capacidade de exercer domínio sobre situações de aprendizagens. Assim, o jogo possibilita uma maior humanização dos sujeitos, e é um fator para a aprendizagem significativa [teoria da aprendizagem proposta por Ausubel]. (SILVA \& MOURA, 2013, s/p.)
\end{abstract}

Além da importância de ser usuário de jogos digitais educativos, o desenvolvimento de jogos digitais pelos próprios alunos pode ser um aspecto explorado no contexto educacional, proporcionando o desenvolvimento da sua capacidade cognitiva (trazendo-lhes novas habilidades e competências), além de ser útil para atraí-los para a área de informática de maneira geral (MELLO \& DANTAS, 2015; VICTAL et al., 2015).

Ao desenvolver esse tipo de jogo, os alunos podem expressar ideias/sentimentos pessoais, reformulando suas concepções sobre o tema abordado e sobre as características próprias do jogo (PAPERT, 1993; KAFAI, 2006). Apesar da relevância em propiciar o desenvolvimento de jogos 
digitais por alunos em sala de aula, essa prática ainda não é muito explorada (BAYTAK \& LAND, 2010).

Considerando-se a possibilidade dos jogos em facilitar a aprendizagem, neste artigo é descrita a iniciativa de criação de um jogo digital educativo sobre o Trabalho Escravo, especificamente no âmbito brasileiro. Tal iniciativa é considerada significante, pois possibilitou, inicialmente, aos alunos desenvolvedores do jogo aprenderem mais sobre esse tema - aliado ao aprendizado das tecnologias para o desenvolvimento do jogo - e, posteriormente, o aprendizado aos alunos/jogadores em ambiente escolar, entre outros.

O restante do artigo está estruturado como segue: na seção 2, é apresentado o contexto do jogo, sendo apresentada a motivação do tema Trabalho Escravo; na seção 3, são comentados trabalhos relacionados; na seção 4, é abordado como o trabalho foi realizado; na seção 5, a descrição e discussão dos resultados; e, por fim, na seção 6, são expostas algumas considerações.

\section{Temática do Jogo}

Caracterizado como a comercialização de pessoas como mercadoria, o trabalho escravo no Brasil iniciou desde a primeira metade do século XVI, sendo decretado o fim do direito de uma pessoa ter propriedade sobre outra apenas em 1888, com a assinatura da Lei Áurea (LIBBY \& PAIVA, 2005).

Entretanto, como divulgado pela Organização Internacional do Trabalho (OIT, 2006), o trabalho semelhante ao escravo se mantém atualmente de outras maneiras: em 1995, o governo brasileiro assumiu, perante o país e a Organização Internacional do Trabalho, a existência do trabalho escravo contemporâneo, tornando-se uma das primeiras nações do mundo a reconhecer oficialmente a ocorrência desse problema - há registro de trabalho escravo em todos os estados brasileiros. Desde 1995, mais de 50 mil trabalhadores foram libertados de situações análogas à de escravidão. Ressalta-se que o Brasil foi o primeiro país condenado, pela Corte Interamericana de Direitos Humanos, por tolerar a escravidão moderna (GARCIA, 2018).

Os problemas sociais, aliados aos problemas econômicos e educacionais, influenciam a crescente prática ilegal de mão de obra. Geralmente, os trabalhadores escravos são migrantes que partem de suas cidades para buscar melhores condições de vida e sustentar suas famílias, atraídos muitas vezes por falsas promessas de aliciadores. Apesar da migração ser um direito humano, muitas vezes está relacionada a violações de direitos, como o tráfico humano. Destacase que, nos casos em que ocorre a fuga do trabalhador que se encontrava em situação de exploração, muitos recorrem a órgãos governamentais ou organizações da sociedade civil para denunciar a violação sofrida (OIT, 2006; SUZUKI \& CASTELI, 2017).

Considerando-se isso, o governo brasileiro tem se empenhado para combater esse tipo de crime, especialmente fiscalizando propriedades e reprimindo empregadores flagrados utilizando mão de obra escrava por meio de punição administrativa/econômica. Todavia, para efetivar a erradicação desse problema, é preciso garantir a prevenção e a assistência ao trabalhador libertado, a partir de ações da sociedade civil e de adoção de políticas públicas por órgãos 
governamentais. Nesse sentido, é possível reverter a situação de pobreza e de vulnerabilidade para que o trabalhador não sofra novamente com outra relação de exploração (OIT, 2006; SUZUKI \& CASTELI, 2017).

Diante dessa temática, percebe-se a importância de abordar nas escolas e destacar, nos dias de hoje, o tema Trabalho Escravo, uma vez que a educação provê um papel preventivo fundamental.

\section{Trabalhos Relacionados}

$\mathrm{Na}$ literatura, há relatos positivos sobre o desenvolvimento de jogos como estratégia de ensino. Oliveira et al. (2015), por exemplo, relataram uma iniciativa para ensinar crianças e professores a criar jogos educativos, usando uma plataforma para o ensino de jogos para a internet.

Outros exemplos são os trabalhos de Shimohara \& Sobreira (2015) e Shimohara et al. (2016), demonstrando que, ao produzir jogos de matemática de maneira colaborativa entre os alunos, utilizando a linguagem Scratch, são favorecidas habilidades próprias do trabalho de programação, além de tornar prazerosa a criação de desafios de matemática. Outro exemplo de jogo desenvolvido utilizando Scratch é apresentado por Lisbôa et al. (2017), envolvendo alunos do $6^{\circ}$ ao $9^{\circ}$ ano do Ensino Fundamental, os quais puderam aprender conteúdos da temática do jogo (descobrimento do Brasil) ao mesmo tempo em que praticavam os conceitos de programação.

Há também trabalhos envolvendo a criação de jogos digitais como inovação no ensino de programação introdutória para jovens no Ensino Médio, como, por exemplo, Pantaleão et al. (2017), que apresentaram o uso do ambiente Robocode como apoio ao ensino da linguagem de programação Java, e Silva \& Carvalho (2016), que relataram um estudo de caso de um jogo desenvolvido em forma de quiz explorando a temática da cultura regional. Outros relatos interessantes são os de Carmichael (2008 apud MELLO \& DANTAS, 2015) e Seabom et al. (2012 apud MELLO \& DANTAS, 2015), que ressaltam a ideia de que o desenvolvimento de jogos eletrônicos por alunos do Ensino Médio estimula a escolha da área da computação como profissão.

No Ensino Superior, há também iniciativas de uso de jogos digitais como estratégias de apoio ao ensino, como o trabalho de Andrade et al. (2016), objetivando a aprendizagem do conceito de Pilha, por parte de alunos da disciplina Estrutura de Dados, a partir do desenvolvimento do Jogo Torre de Hanói em versão digital.

É conveniente destacar que Pietruchinski et al. (2011) realizaram uma revisão sistemática dos trabalhos publicados no Simpósio Brasileiro de Informática na Educação (SBIE), entre 2001 e 2010, sobre jogos aplicados em contextos educacionais, apresentando que este tema é tratado em apenas 5,4\% das publicações, sendo a maioria relacionada ao ensino de Ciência da Computação.

Nesse seguimento, destaca-se o trabalho de Silva et al. (2015), que se assemelha ao apresentado neste artigo ao fazer com que os desenvolvedores do jogo (alunos da área de 
informática/computação) apliquem conhecimentos técnicos ao mesmo tempo em que aprendem temas não comumente trabalhados na grade curricular de seus cursos. No trabalho de Silva et al. (2015), os estudantes cursavam Licenciatura em Computação, e desenvolveram um jogo sobre Política, enquanto, na experiência relatada neste artigo, os estudantes são alunos de um curso técnico em informática, sendo o jogo sobre Trabalho Escravo. Silva et al. (2015), contudo, não enfocam em seu artigo o aprendizado/desempenho dos alunos desenvolvedores.

Em relação a publicações sobre jogos digitais como instrumentos de aprendizagem nas diversas áreas do conhecimento, há várias iniciativas que podem ser citadas.

Freitas e Adamatti (2016) desenvolveram um jogo em forma de quiz para o ensino teórico de direito do trabalho. Müller et al. (2007), Reis et al. (2008) e Teixeira et al. (2016) são exemplos de autores que usaram jogos digitais no âmbito da história do Brasil - respectivamente sobre: a retirada da Laguna (parte da Guerra do Paraguai); a revolução da Cabanagem; a fundação da cidade de Marabá-PA e seu primeiro ciclo econômico.

No campo das ciências biológicas e da saúde, encontram-se trabalhos envolvendo o uso de jogos digitais visando o entendimento sobre consciência ecológica (COSTA et al., 2006; DE AZEVEDO et al., 2011), dengue (BUCHINGER \& HOUNSELL, 2015), anatomia humana (LEMOS et al., 2017), condições de higiene (INÁCIO JÚNIOR \& FELIX, 2017), entre outros aspectos.

Também há vários trabalhos sobre jogos digitais explorando conceitos matemáticos (LEITÃO et al., 2012; MACÊDO et al., 2017; SOARES \& CASTRO, 2017) e linguísticos (LEVAY et al., 2015; GASPAR et al., 2016; OLIVEIRA et al., 2017; SARINHO, 2017).

Além disso, é interessante citar a existência de iniciativas de uso de jogos digitais para a educação inclusiva/assistiva, envolvendo, por exemplo, deficientes visuais (JUNQUEIRA et al., 2015; SANTANA et al., 2017), autistas (MOURA et al., 2016; MOITA et al., 2017), disléxicos (SANTOS et al., 2014) e pacientes de serviços de oncologia (SANTOS et al., 2016).

Em busca de publicações sobre Trabalho Escravo no âmbito de Informática na Educação, foi escolhida a string de busca escrav* - por contemplar palavras como "escravo" e "escravidão" - e utilizada nos mecanismos de busca on-line destes veículos de publicação científica brasileiros (eventos e periódicos voltados para a educação e informática/novas tecnologias): Informática na Educação: Teoria \& Prática (IETP), Revista Brasileira de Informática na Educação (RBIE), Revista Novas Tecnologias na Educação (RENOTE), Simpósio Brasileiro de Informática na Educação (SBIE) e Workshop de Informática na Escola (WIE). Apesar do termo abrangente utilizado na busca, só houve 1 (um) retorno nesses veículos de publicação: um artigo nos Anais do SBIE 2017, que apresenta uma ferramenta de geração automática de questões e usa o tema "Trabalho Escravo" para exemplificar (não satisfazendo o intuito da busca). Essa escassez de trabalhos ressalta a importância da iniciativa apresentada neste artigo.

Todavia, mesmo não publicados em veículos de publicação científica, há conhecimento de dois jogos digitais brasileiros nesta temática: o jogo "Escravo, nem pensar!"1 e o jogo "Trabalho

\footnotetext{
${ }^{1}$ http://escravonempensar.org.br/2014/05/escravo-nem-pensar-lanca-jogo-digital-sobre-trabalho-escravo-contemporaneo/
} 
Livre"2. Ambos os jogos foram publicados após a realização da experiência relatada neste artigo, sendo importante destacar que o primeiro deles foi criado pelo projeto que serviu de inspiração dos alunos desenvolvedores participantes desta experiência (detalhes na seção 4).

Além do jogo apresentado contemplar diferente jogabilidade em comparação aos jogos citados anteriormente, a experiência apresentada neste artigo é relevante, pois, além de criar um jogo para divulgar a temática da escravidão brasileira, possibilitou o aprendizado de conceitos e tecnologias, presentes nas ementas de um curso técnico em informática, de forma que os alunos/desenvolvedores puderam praticá-los ao mesmo tempo em que aprenderam sobre o Trabalho Escravo no Brasil (conceitos não presentes nessas ementas).

\section{Método}

O trabalho apresentado neste artigo surgiu como requisito do curso técnico em informática da Escola Técnica Redentorista (instituição privada de Campina Grande - PB, com cursos técnicos de nível médio), a qual propõe a seus alunos apresentarem um projeto a partir de um determinado tema gerador. Com a definição de "Tráfico Humano" como tema, foram formados os grupos de alunos e escolhidos os professores orientadores.

Um desses grupos, composto por 6 alunos, em conversa com seu professor orientador, interessou-se pelo contexto específico Trabalho Escravo e iniciou uma busca por possibilidades a se trabalhar. Durante essa busca, foram encontradas informações sobre o projeto "Escravo, nem pensar!"3, coordenado pela ONG Repórter Brasil.

O grupo descobriu a existência de um jogo de tabuleiro educativo (Figura 1) desenvolvido por esse projeto, o qual possui o mesmo nome ("Escravo, nem pensar!"), e pensou em realizar um jogo digital adaptado. Com essa ideia em mente, os alunos contataram os responsáveis pelo projeto "Escravo, nem pensar!", que demonstraram interesse pela iniciativa e enviaram o jogo de tabuleiro para que o grupo pudesse entender, ao jogá-lo, como funcionava a estratégia pedagógica pretendida pelos idealizadores do jogo.

\footnotetext{
2 http://www.mptgames.com.br/trabalholivre/

3 http://escravonempensar.org.br/
} 
Figura 1 - Ilustração do jogo de tabuleiro "Escravo, nem pensar!".



Fonte: ENP!, 2013.

Com a devida autorização e assinatura de um termo de consentimento - que explicava o objetivo do trabalho sem fins lucrativos e explicitava a concordância com a utilização de elementos do jogo pelo grupo - , foram iniciadas as atividades de desenvolvimento.

É importante ressaltar que, devido ao escopo do projeto da escola, os alunos se dedicaram na implementação do jogo durante dois módulos (aproximadamente 1 ano), sendo realizada, ao final de cada módulo, uma apresentação dos resultados obtidos até o momento.

Diante disso, o grupo definiu os aspectos metodológicos para se desenvolver o jogo e o cronograma das atividades a serem realizadas em cada módulo, com base nas tecnologias aprendidas com o andamento do curso técnico em informática.

Nesse contexto, foi decidido, para o módulo I, utilizar a linguagem de programação Python para a criação de um protótipo do jogo. Para a utilização de Python, foi utilizado o ambiente IDLE e, para a modelagem do Banco de Dados (BD), foi utilizado o software brModelo (CÂNDIDO, 2005).

Para o módulo II, utilizaram a linguagem de programação Java para implementação do jogo. Além disso, foi escolhido o MySQL como Sistema de Gerenciamento de Banco de Dados (SGBD), para armazenar os dados necessários.

As atividades foram desenvolvidas principalmente em um dos laboratórios de informática da escola, facilitando o acompanhamento do professor orientador e da coordenação da escola, de modo geral. Além desse ambiente, os alunos também utilizaram seus computadores pessoais.

Para avaliação das atividades, o grupo realizou duas apresentações (ao final do módulo I e do módulo II) para parte do corpo docente e discente da Escola Técnica Redentorista aproximadamente 70 alunos e 5 professores em cada módulo. Além disso, entre os dois módulos, o grupo apresentou uma versão do jogo na Mostra de Projetos realizada pela Escola Técnica Redentorista, aberta à comunidade externa à escola. 


\section{Resultados e Discussão}

Esta seção contempla duas subseções, separando os resultados das atividades do grupo em cada módulo.

\subsection{Resultados Iniciais}

Dentre as primeiras atividades e, consequentemente, um dos primeiros resultados foi, a partir da especificação do tema, a definição das regras do jogo pelos alunos desenvolvedores. No Quadro 1, encontra-se uma adaptação da descrição posta no relatório do grupo, entregue aos professores avaliadores.

Quadro 1 - Regras do jogo.

Inicialmente, a ideia principal era adaptar tudo do jogo de tabuleiro, mas por questão de tempo houve uma simplificação das regras do jogo, deixando-o mais simples e fácil de ser entendido. Sendo assim, o que permaneceu do jogo original foi tão somente o seu nome comercial.

$(\ldots)$

Foi definido iniciá-lo com um pequeno texto informativo sobre a Escravidão no Brasil e como o jogo funciona, permitindo posteriormente ao jogador escolher uma região do mapa brasileiro que deseja começar. Ao realizar a escolha, são mostradas perguntas de múltipla escolha relacionadas ao trabalho escravo na região escolhida. Ao término do jogo, são apresentadas as pontuações por região brasileira.

Fonte: elaborado pelo autor — adaptado de XAVIER et al. (2014).

Com a lógica do jogo definida, o grupo planejou como projetar o Banco de Dados (BD). Em relação à modelagem conceitual, usando a teoria de bancos de dados relacionais ${ }^{4}$, o grupo elaborou um esquema Entidade-Relacionamento para indicar que, para cada região, haverá várias questões (sendo cada questão específica de determinada região), e que, para cada questão, haverá 3 alternativas possíveis, sendo apenas uma correta.

Após o BD planejado, o grupo desenvolveu uma versão inicial do jogo em Python com interface modo texto, ou seja, ainda sem interface gráfica. Uma demonstração dessa versão está ilustrada na Figura 2.

\footnotetext{
${ }^{4}$ Um banco de dados relacional é composto de tabelas (relações). Os sistemas de gerência de banco de dados relacionais dominam o mercado atualmente (HEUSER, 2009).
} 
Figura 2 - Demonstração de execução do jogo com interface modo texto.



Fonte: adaptada de XAVIER et al. (2014).

Além disso, o grupo elaborou um protótipo da interface gráfica (Figura 3) a ser implementada no módulo seguinte.

Figura 3 - Protótipo da interface gráfica do jogo.



Fonte: adaptada de XAVIER et al. (2014).

Como referido na seção 4, o grupo apresentou a discentes e docentes da escola os artefatos mencionados anteriormente nesta seção. Os discentes presentes demonstraram uma boa receptividade em relação à ideia e à versão de demonstração do jogo, mesmo não contendo ainda interface gráfica. Além disso, os cinco docentes presentes (dentre eles o professor orientador e o coordenador do curso), responsáveis por realizarem uma avaliação do projeto do grupo, dentre os desempenhos/conceitos possíveis - a saber: Ótimo, Bom, Regular ou 
Insuficiente - definiram o projeto como Ótimo, ressaltando a atuação satisfatória dos alunos envolvidos.

\subsection{Resultados Finais}

No módulo II do curso, ao terem contato com a linguagem de programação Java, os alunos iniciaram a implementação do jogo nesta linguagem, utilizando o ambiente de desenvolvimento Eclipse com o plugin WindowBuilder para interface gráfica.

A partir das ideias do módulo I, os alunos/desenvolvedores criaram uma versão (Figura 4) que foi apresentada na Mostra de Projetos realizada pela Escola Técnica Redentorista.

Apesar das apresentações dessa Mostra não terem um caráter avaliativo oficial, serviu para que os alunos ouvissem as impressões e sugestões de outros alunos da escola - de variados cursos técnicos - além de outros professores e pessoas externas à escola que assistiram à apresentação e jogaram a versão criada. 
Figura 4 - Telas da versão do jogo apresentada na Mostra de Projetos.



Fonte: elaborada pelo autor - adaptada de XAVIER et al. (2014). 
No Quadro 2, são apresentadas algumas opiniões de alunos que participaram da Mostra de Projetos.

Quadro 2 - Opiniões de alunos de outras turmas que jogaram a versão apresentada na Mostra de Projetos.

\begin{tabular}{|c|}
\hline $\begin{array}{c}\text { "Parabéns, o jogo ficou bom e interessante." } \\
\text { (Aluno da Escola Técnica Redentorista) }\end{array}$ \\
\hline "O jogo ficou bom, mas as perguntas são muito difíceis." \\
(Aluna da Escola Técnica Redentorista) \\
"O jogo é bom, desafiador, o participante fica entusiasmado e tenso em querer obter \\
uma boa pontuação. O design pode ser melhorado, mas está sendo bem desenvolvido." \\
(Aluna da Escola Técnica Redentorista)
\end{tabular}

Fonte: elaborado pelo autor - adaptado de XAVIER et al. (2014).

Em relação aos comentários dos alunos/jogadores, nota-se que o jogo, ao incluir perguntas "difíceis" (sobre fatos não tão conhecidos), desafia o aluno a saber qual resposta correta para evitar cometer erros futuros. Assim, amplia o conhecimento desses alunos sobre o tema.

Após essa demonstração, e com base nos diversos comentários e sugestões ouvidas, o grupo se reuniu para decidir o que permaneceria e o que seria modificado.

É significante citar que um dos professores avaliadores do Módulo I sugeriu ao grupo pensar em algum tipo de "recompensa", no caso do aluno/jogador acertar muitas questões. Essa funcionalidade - que havia sido pensada, mas ainda não planejada/implementada pelo grupo foi considerada nesta versão do jogo na forma de ranking, deixando visível aos outros jogadores aqueles que obtiveram melhor desempenho, como forma de estimular os alunos/jogadores a acertarem mais e, consequentemente, jogarem e aprenderem mais.

Na Figura 5, encontram-se partes gráficas da versão final do jogo. Primeiramente, o jogador pode ter acesso às regras (opção Ajuda), começar o jogo (opção Iniciar) ou saber informações relativas ao projeto (opção Projeto), incluindo dados da ONG Repórter Brasil. Ao Iniciar, o jogador deve inserir seu nome e idade, informações que serão armazenadas e disponibilizadas ao final do jogo, na tela de Ranking, em ordem dos jogadores que obtiveram as maiores pontuações. Após esse preenchimento, o jogador visualiza o mapa, que contém botões em cada região e, a partir destes, acessa as questões de múltipla escolha. Antes de iniciar as perguntas por região, é apresentada uma breve descrição desta, como forma de compartilhar algumas informações históricas. Ao final das questões de cada região, o jogador é direcionado ao mapa, podendo visualizar sua pontuação até o momento, escolher outra região para jogar, ou concluir o jogo. Ao concluir, o usuário é informado de sua pontuação final e direcionado ao Ranking, podendo recomeçar o jogo. 
Apesar da existência do professor orientador, é importante ressaltar que este buscou não influenciar demais nas decisões dos alunos, a exemplo de questões de interface do jogo com o usuário, uma vez que aspectos como proatividade, iniciativa e desenvolvimento por parte dos alunos são incentivados neste tipo de projeto. 
Figura 5 - Telas da versão final do jogo.
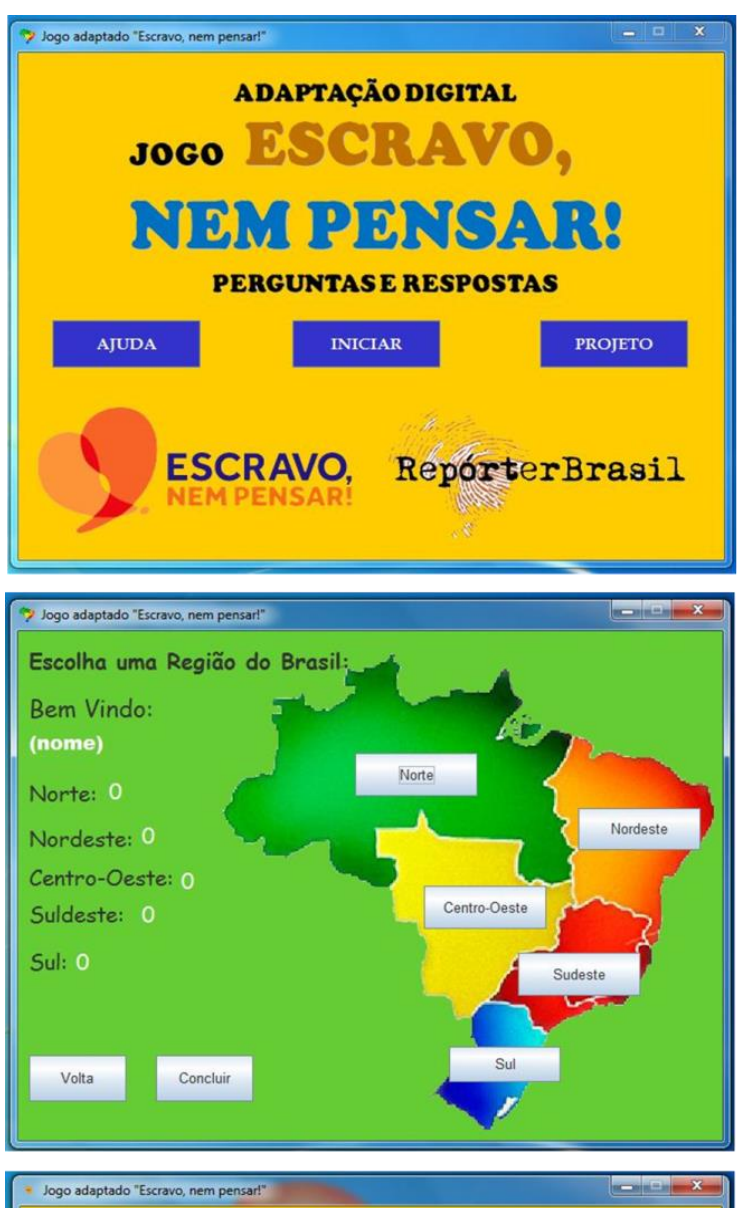

Pergunta 1 - Região Nordeste

Na primeira metade do século XVI, os europeus e até

brasileiros traziam negros africanos para sustentar a mão de

obra da principal produção agrícola do nordeste, que produção

A) Produção do Sisal

B) Produção de cana de açúcar

C) Produção de soja

$$
\text { Avançar }
$$



$$
\text { Ajuda - (Como jogar) }
$$

- Escolha uma das regiões na qual você deseja começar.

- Depois de escolher irá aparecer um texto sobre ela.

- Depois responda as perguntas que irá aparecer.

- Acertando as perguntas você irá ganhar 10 pontos.

- Errando as perguntas você irá perder 5 pontos.

Voltar


Fonte: elaborada pelo autor - adaptada de XAVIER et al. (2014). 
Ao final do módulo II, ao apresentarem os novos resultados à parte do corpo docente e discente da escola, novamente o corpo discente demonstrou interesse, especialmente agora, devido à interface mais amigável. Os docentes envolvidos no processo de avaliação julgaram novamente o trabalho com o desempenho/conceito Ótimo.

Além dos bons comentários dos alunos/jogadores e da avaliação formal por parte dos professores relacionada ao aprendizado dos alunos/desenvolvedores sobre o Trabalho Escravo no Brasil (definindo desempenho/conceito Ótimo em ambos os módulos), foram gerados alguns gráficos (Figuras 6 e 7) como forma de analisar o impacto possível da criação desse jogo digital educativo no aprendizado desses alunos/desenvolvedores em relação a conceitos intrínsecos do curso técnico em informática.

Na Figura 6, são apresentados os gráficos com o desempenho/conceito dos alunos envolvidos nesse projeto em relação aos outros alunos da turma, especificamente nas disciplinas que envolviam diretamente os conceitos técnicos para a implementação do jogo - Introdução à Programação (IP), Banco de Dados Relacionais (BD) e Desenvolvimento de Aplicativos com Banco de Dados (DABD).

Figura 6 - Gráficos relativos aos desempenhos/conceitos da turma, em disciplinas voltadas à programação, cujos alunos/desenvolvedores fazem parte.

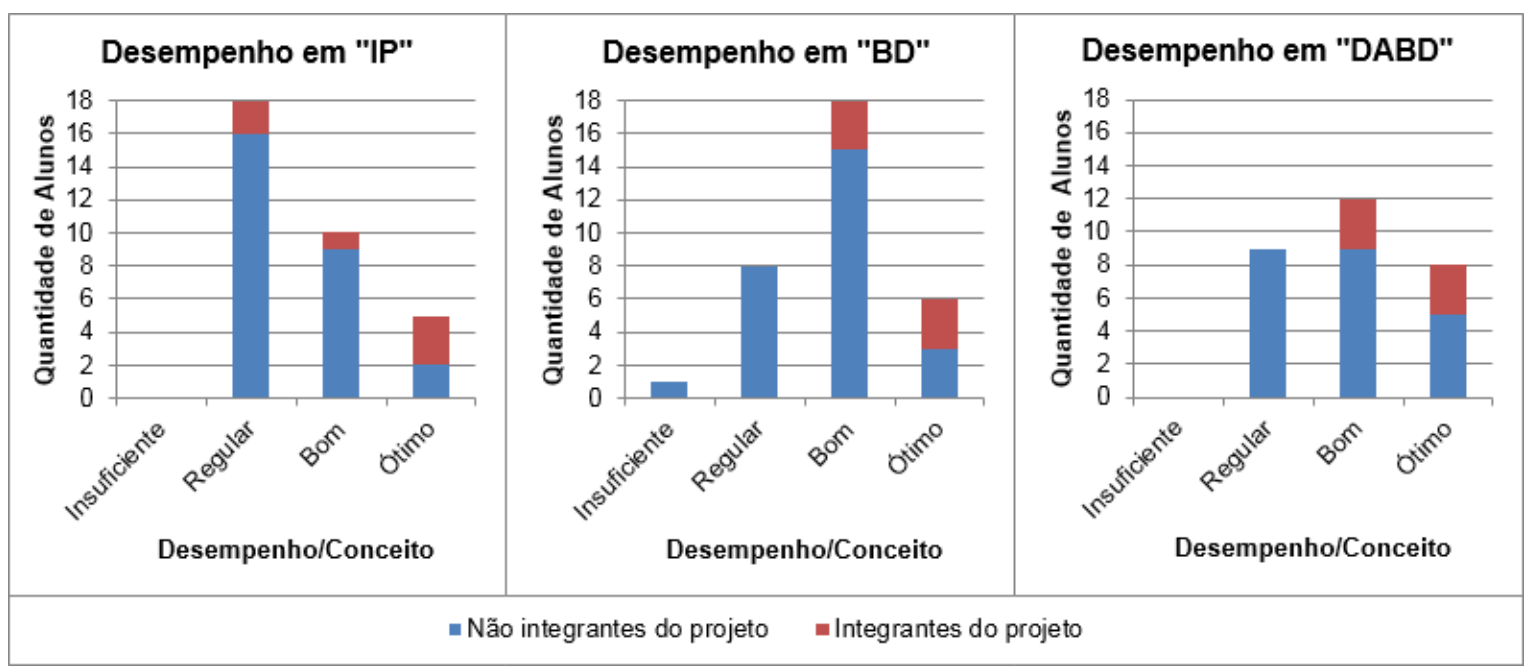

Fonte: elaborada pelo autor.

Na Figura 7, estão os gráficos em relação ao desempenho/conceito geral dos módulos I e II, definidos pelos membros do Conselho de Classe - formado pelos professores de todas as disciplinas de cada módulo, pelo coordenador do curso e pela diretora pedagógica - com base nos desempenhos/conceitos em todas as disciplinas. 
Figura 7 - Gráficos relativos aos desempenhos/conceitos gerais dos módulos I e II da turma cujos alunos/desenvolvedores fazem parte.

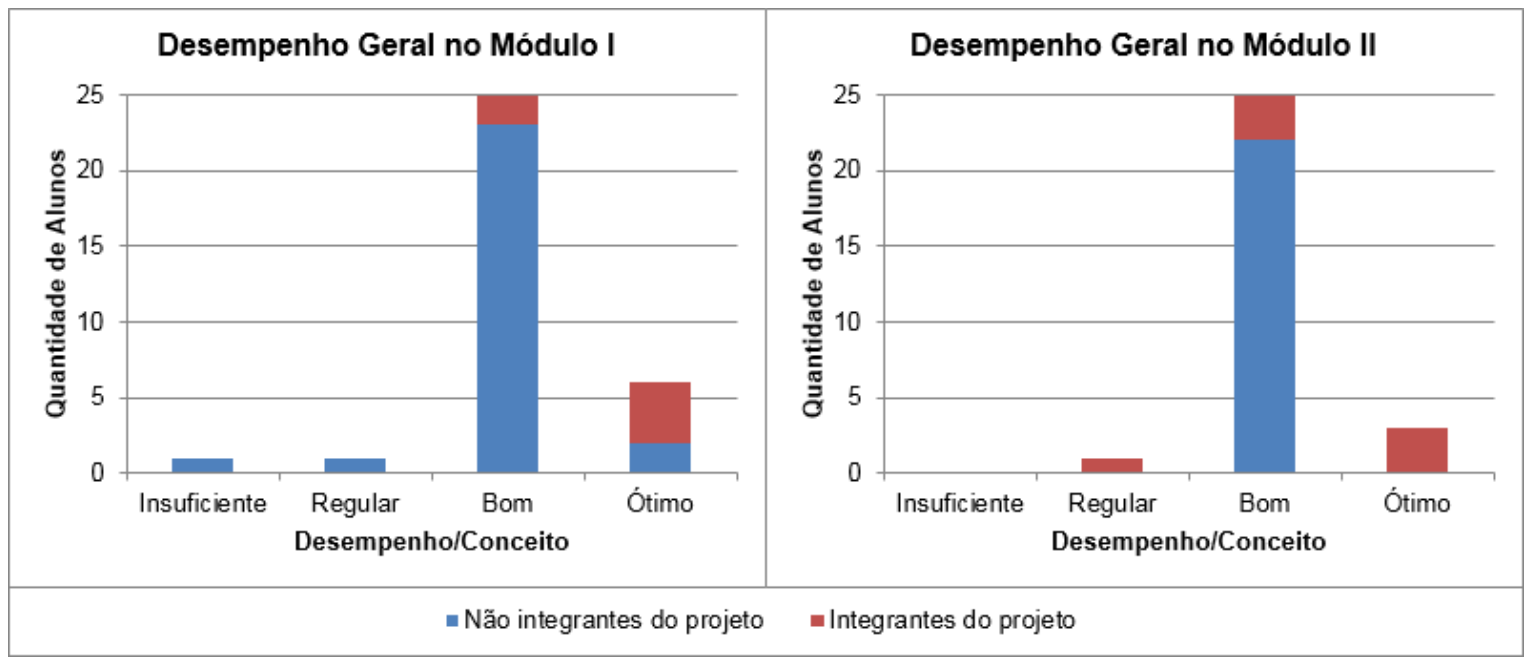

Fonte: elaborada pelo autor.

Ressalta-se que todos os alunos da turma desenvolveram projetos nesses módulos, mas apenas este grupo implementou um jogo digital educativo enquanto projeto.

Na Figura 6, em geral, percebe-se que metade dos alunos do grupo de desenvolvimento do jogo tiveram o melhor resultado possível (Ótimo); em relação aos outros, embora 2 deles tenham recebido conceito Regular em IP, nas outras disciplinas apresentadas obtiveram conceito Bom, um desempenho melhor que uma parte considerável da turma. É importante destacar que essas disciplinas ocorreram sequencialmente - IP na primeira metade do módulo I, BD na segunda metade do módulo I, e DABD durante todo o módulo II - , sendo desenvolvidas apenas as ideias do jogo durante a disciplina IP.

Na Figura 7, percebe-se um destaque dos alunos participantes da criação do jogo dentre os que obtiveram melhor desempenho na turma em ambos os módulos. Apesar de no módulo 2 um dos integrantes ter obtido o mais baixo desempenho da turma (devido principalmente a suas faltas), por outro lado, os únicos alunos que obtiveram conceito Ótimo da turma são desenvolvedores do jogo.

Embora não seja possível afirmar veementemente que os alunos que desenvolveram o jogo digital educativo tiveram melhor desempenho em comparação àqueles que não desenvolveram, os dados das Figuras 6 e 7 demonstram que esse tipo de projeto pode impactar positivamente o desempenho discente em disciplinas que, embora não tenham foco em desenvolvimento de jogos, abordam os conceitos e tecnologias úteis para esse desenvolvimento. Além disso, acreditase que a motivação no processo de ensino e aprendizagem, demonstrada cotidianamente por parte da maioria dos alunos/desenvolvedores, refletiu no desempenho geral de cada módulo. Como afirmam Oliveira et al. (2015, p. 638), "Quando a programação está ligada à construção de jogos, a aprendizagem é motivada por um prazer lúdico. Este prazer leva o aprendiz a perseverar na busca de seu intento, e o faz avançar superando as frustrações advindas dos erros.". 
Dessa forma, percebe-se a contribuição tecnológica deste trabalho - por meio da criação do jogo digital educativo - , além da contribuição para o processo de ensino e aprendizagem durante o desenvolvimento da implementação do jogo.

\section{Considerações Finais}

Os resultados demonstram a importância de incentivar alunos, especialmente em cursos profissionalizantes, a desenvolver projetos que, além de praticar conceitos técnicos, estejam aliados à preocupação com a educação e questões sociais e, dessa forma, estender seu conhecimento à comunidade ainda enquanto discentes. Como defendem Oliveira et al. (2015, p. 637), "Jogos são divertidos e podem se tornar a melhor forma de educação. [...] Programando jogos, estudante e professores libertam sua criatividade e podem inovar sua própria educação.".

Este trabalho insere-se no âmbito de pesquisa na área de jogos digitais educativos com cunho social e cultural, enfatizando o uso de tecnologias na educação com base no entretenimento digital, garantindo que o ambiente escolar esteja acompanhando e sendo parte de transformações socioculturais, especialmente com base no lúdico.

Analisando o problema do trabalho escravo contemporâneo no Brasil, e com o entendimento de como as organizações influenciam a formulação de políticas nacionais nas esferas sociais, econômicas ou políticas, a principal meta do grupo desenvolvedor do jogo consistiu em contribuir diretamente para a educação - que tem papel fundamental para a divulgação de informações —, almejando colaborar com a diminuição no número de trabalhadores aliciados para o trabalho escravo.

Durante os contatos com a equipe do projeto "Escravo, nem pensar!", esta divulgou que, além de possuírem o jogo de tabuleiro, estavam iniciando a divulgação de um jogo digital educativo (citado na Seção 3). Entretanto, as regras e o objetivo desse jogo são bem distintos do jogo idealizado pelos alunos - ou seja, ambos são jogos digitais adaptados do jogo de tabuleiro, mas possuem diferente jogabilidade.

Por fim, é possível afirmar que a estratégia de fazer com que os alunos implementem um jogo sobre trabalho escravo fez com que eles adquirissem um conhecimento amplo dessa área, além de conteúdos específicos de sua formação (no caso, futuros técnicos em informática). Segundo Santos \& Bourscheidt (2014, p. 28), "os jogos ganharam espaço no ambiente educacional, principalmente por permitir a participação ativa do aprendiz, experimentando e construindo conhecimento". Nesse sentido, é interessante citar as seguintes considerações de Golart e seus colaboradores:

Reforçar o interesse nas experiências de aprendizagem presentes nos jogos digitais contribui com a compreensão de que os modos clássicos de metodologias de ensino, baseados em processos unilaterais de transmissão de conhecimento, não são exclusivos e que há outras relações possíveis entre sujeitos e produção de conhecimento, entendendo existir diferentes tipos de performances criando essas relações, assim como diferentes formas de constituir e habitar os espaços coletivos. Nessa direção, é importante poder afirmar a potência dos espaços de afinidade em torno dos jogos, uma vez que a multiplicidade de configurações e de possibilidades de participação produzidas nesses espaços ajudam a pensar outras formas coletivas de produção de conhecimento. (Golart et al., 2017, p. 114) 
A execução deste trabalho, com os resultados apresentados, demonstra que o desenvolvimento e programação de jogos pelos alunos pode potencializar o aprendizado de determinados conteúdos. A experiência possibilitou um aprendizado diferenciado e significativo de conceitos e tecnologias (tais como Lógica de Programação, Python, Java, Banco de Dados) de forma que os alunos os praticaram e simultaneamente aprenderam sobre o Trabalho Escravo no Brasil, além de deixarem estes alunos mais motivados ao produzirem um jogo educativo para outros alunos e para a comunidade em geral aprenderem, jogando, sobre um tema de importância universal.

\section{Agradecimento}

À direção e ao corpo discente e docente da Escola Técnica Redentorista (ETER), além da coordenação do curso técnico em informática. A Rodrigo Felipe Agostinho, Tiago Ferreira Dídimo, Rogério da Costa Lima, José de Arimatéa Santos Junior, Thiago Matheus Araújo Dias, e Germano Ramalho Xavier. À ONG Repórter Brasil, especialmente à equipe do projeto "Escravo, nem pensar!".

\section{Referências}

ANDRADE, T.; GLAY, R. R.; LOPES, G. S.; COSTA, R. L. Implementação do Jogo Torre de Hanói como Estratégia de Aprendizagem de Pilha. Anais do XXVII Simpósio Brasileiro de Informática na Educação (SBIE), p. 1311-1315, 2016. Disponível em: <http://www.br-ie.org/pub/index.php/sbie/article/view/6819/4704>. Acesso em: 12 jan. 2018.

BAYTAK, A.; LAND, S. M. A case study of educational game design by kids and for kids. Procedia-Social and Behavioral Sciences, v. 2, n. 2, p. 5242-5246, 2010.

BUCHINGER, D.; HOUNSELL, M. S. O Aprendizado através de um Jogo Colaborativo-Competitivo contra Dengue. Anais do XXVI Simpósio Brasileiro de Informática na Educação (SBIE), p. 439-448, 2015. Disponível em: <http://www.br-ie.org/pub/index.php/sbie/article/view/5286/3661>. Acesso em: 11 jan. 2018.

CÂNDIDO, C. H. brModelo: Ferramenta de Modelagem Conceitual de Banco de Dados. Dissertação de PósGraduação em Banco de Dados - Univag, UFSC, 2005. Disponível em: <http://sis4.com/brModelo/monografia/monografia.htm>. Acesso em: 13 jan. 2018.

COSTA, D. F.; FAVERO, E. L.; CUNHA, W. P. Baiuka - Um jogo educativo infantil usando agentes inteligentes na avaliação das inteligências múltiplas. Anais do XII Workshop de Informática na Escola (WIE), p. 111-119, 2006. Disponível em: <http://www.br-ie.org/pub/index.php/wie/article/view/881/867>. Acesso em: 13 jan. 2018.

DA SILVA NETO, S. R.; SANTOS, H. R. M.; DE SOUZA, A. A.; DOS SANTOS, W. O. Jogos Educacionais como Ferramenta de Auxílio em Sala de Aula. Anais do XIX Workshop de Informática na Escola (WIE), p. 130-139, 2013. Disponível em: <http://www.br-ie.org/pub/index.php/wie/article/view/2634/2288>. Acesso em: 13 jan. 2018.

DE AZEVEDO, R. R.; DE SOUZA, I.; DA SILVA, A. R. A.; NEGREIROS, G.; FREITAS, F.; JÚNIOR, I. H. F. Ensino e Aprendizagem de Educação Ambiental Através de um Jogo Eletrônico. Anais do XVII Workshop de Informática na Escola (WIE), p. 1382-1385, 2011. Disponível em: <http://www.brie.org/pub/index.php/wie/article/view/1993/1752>. Acesso em: 13 jan. 2018. 
ENP! - Equipe Escravo, nem pensar! Programa educativo da ONG Repórter Brasil lança o jogo "Escravo, nem pensar!". 2013. Disponível em: <http://escravonempensar.org.br/2013/07/programa-educativo-da-ongreporter-brasil-lanca-o-jogo-escravo-nem-pensar/>. Acesso em: 11 jan. 2018.

FREITAS, V. C. B.; ADAMATTI, D. Educa Direito: Um Jogo Sério para o Ensino de Direito do Trabalho. Brazilian Journal of Computers in Education (Revista Brasileira de Informática na Educação - RBIE), v. 24, n. 03, p. 1-15, 2016. Disponível em: <http://www.br-ie.org/pub/index.php/rbie/article/view/6441/4979>. Acesso em: 12 jan. 2018.

GARCIA, M. F. Brasil foi o primeiro país condenado por escravidão moderna. 2018. Disponível em: <https://observatorio3setor.org.br/noticias/brasil-foi-o-primeiro-pais-condenado-pela-cidh-por-escravidaomoderna >. Acesso em: 10 set. 2018.

GASPAR, W.; OLIVEIRA, E. H. T.; CURY, D. NaPontaDaLíngua: Um Aplicativo para Apoiar o Processo de Ensino-Aprendizagem da Língua Portuguesa. Anais do XXVII Simpósio Brasileiro de Informática na Educação (SBIE), p. 60-69, 2016. Disponível em: <http://www.brie.org/pub/index.php/sbie/article/view/6686/4574>. Acesso em: 11 jan. 2018.

GOLART, J. B.; KROEFF, R. F. S.; GAVILLON, P. Q. Aprendizagem Colaborativa e Violência Entre Jogadores de League of Legends. Informática na educação: teoria \& prática, Porto Alegre, v. 20, n. 1, p. 103-117, 2017. Disponível em: <http://seer.ufrgs.br/index.php/InfEducTeoriaPratica/article/view/67988/41087>. Acesso em: 11 jan. 2018.

HEUSER, C. A. Projeto de banco de dados. 6. ed. Porto Alegre: Bookman, 2009. 282p. ISBN: 978-85-7780382-8.

INÁCIO JÚNIOR, F. A.; FELIX, Z. C. Proposta de um Jogo Sério para Simular Condições de Higiene e Doenças em um Ambiente Familiar em Comunidades Carentes. Anais do XXIII Workshop de Informática na Escola (WIE), p. 1212-1216, 2017. Disponível em: <http://www.brie.org/pub/index.php/wie/article/view/7336/5134>. Acesso em: 11 jan. 2018.

JUNQUEIRA, M. A. P.; CUNHA, L, F.; MACHADO, A. F. V.; MOREIRA, J. G. R. Uma Proposta de Jogo Assistivo para Dispositivos Móveis em Prol da Inclusão Digital de Deficientes Visuais. Anais do XXI Workshop de Informática na Escola (WIE), p. 554-563, 2015. Disponível em: <http://www.brie.org/pub/index.php/wie/article/view/5098/3503>. Acesso em: 12 jan. 2018.

KAFAI, Y. B. Playing and Making Games for Learning. Games and Culture, v. 1, n. 1, p. 36-40, 2006.

LeitÃO, A. H. B.; GONÇALVES, G. G. A.; Ribeiro, W. M.; DE OliveirA, B. C.; SAlgueiro, V. S. N.; MADEIRO, F. Terra das Cores: Uma Proposta de Jogo Educacional Infantil para o Exercício do Raciocínio Lógico-Matemático. Anais do XXIII Simpósio Brasileiro de Informática na Educação (SBIE), p. 1-10, 2012. Disponível em: <http://www.br-ie.org/pub/index.php/sbie/article/view/1775/1536>. Acesso em: 13 jan. 2018.

LEMOS, W. B.; FARIAS JUNIOR, I. H.; CAMPOS FILHO, A. S. Uma Proposta de um Serious Game no Auxílio do Aprendizado da Anatomia Humana. Anais do XXVIII Simpósio Brasileiro de Informática na Educação (SBIE), p. 2017. 655-664, Disponível em: <http://www.brie.org/pub/index.php/sbie/article/view/7594/5390>. Acesso em: 11 jan. 2018.

LEVAY, P. B.; FALCÃO, T. P.; DINIZ, J. R. B.; SOUZA, R. Uma Experiência de Uso de Jogos Digitais como Ferramentas de Apoio para Aprendizagem de Inglês por Crianças. Anais do XXI Workshop de Informática na Escola (WIE), p. 207-216, 2015. Disponível em: <http://www.brie.org/pub/index.php/wie/article/view/5022/3432>. Acesso em: 11 jan. 2018.

LIBBY, D. C.; PAIVA, E. F. A escravidão no Brasil: relações sociais, acordos e conflitos. 2a. ed. São Paulo: Moderna. v. 1. 96p. 2005.

LISBÔA, E. S.; MONTE-ALTO, H. H. L. C.; SILVA, M. L. Clubes de Programação com Scratch nas Escolas e a Interdisciplinaridade. Anais do XXIII Workshop de Informática na Escola (WIE), p. 1174-1178, 2017. Disponível em: <http://www.br-ie.org/pub/index.php/wie/article/view/7328/5126>. Acesso em: 12 jan. 2018. 
MACÊDO, P. H.; LIMA, M. M.; SANTOS, W. Jogo Digital como Auxílio no Estudo da Matemática: Um Estudo de Caso com Estudantes do Ensino Fundamental I. Anais do XXIII Workshop de Informática na Escola (WIE), p. 548-557, 2017. Disponível em: <http://www.br-ie.org/pub/index.php/wie/article/view/7273/5071>. Acesso em: 12 jan. 2018.

MELLO, T. S.; DANTAS, A. GameMaking: A Methodology to Teach Informatics for Middle School Students through the Creation of Digital Games. Brazilian Journal of Computers in Education (Revista Brasileira de Informática na Educação - RBIE), v. 23, n. 01, p. 197-207, 2015. Disponível em: <http://www.brie.org/pub/index.php/rbie/article/view/2459/2848>. Acesso em: 11 jan. 2018.

MOITA, F. M. G. S. C.; VIANA, L. H.; MEDEIROS, F. M.; CANDIDO, V. M. A. Design e desenvolvimento de um game assistivo para autistas. Anais do XXVIII Simpósio Brasileiro de Informática na Educação (SBIE), p. 1057-1066, 2017. Disponível em: <http://www.br-ie.org/pub/index.php/sbie/article/view/7634/5430>. Acesso em: 12 jan. 2018.

MOURA, D. L. L.; FILHO, D. L. S. O.; SILVA, A. J. G.; PAIVA, P. V. V.; SALES, T. B. M.; CAVALCANTE, R. C.; QUEIROZ, F. S. TEO: Uma suíte de jogos interativos para apoio ao tratamento de crianças com autismo. Anais do XXVII Simpósio Brasileiro de Informática na Educação (SBIE), p. 627-636, 2016. Disponível em: <http://www.br-ie.org/pub/index.php/sbie/article/view/6744/4631>. Acesso em: 12 jan. 2018.

MÜLLER, R. M.; CAVALCANTE, G. D.; DOS SANTOS, L. A. Laguna - Aprendendo sobre a Guerra do Paraguai com jogo educativo. Anais do XIII Workshop de Informática na Escola (WIE), p. 256-263, 2007. Disponível em: <http://www.br-ie.org/pub/index.php/wie/article/view/926/912>. Acesso em: 13 jan. 2018.

OIT - Organização Internacional do Trabalho. Trabalho escravo no Brasil do Século XXI. Coordenação do estudo: Leonardo Sakamoto. Brasília, OIT, 2006. ISBN: 978-92-2-819328-2. Disponível em: <http://www.oitbrasil.org.br/sites/default/files/topic/forced_labour/pub/trabalho_escravo_no_brasil_do_\% 20seculo_\%20xxi_315.pdf>. Acesso em: 13 jan. 2018.

OLIVEIRA, C. E. T.; NOGUEIRA, E. C.; MOTTA, C. L. R.; MEIRELES, L. B. Relação estudanteprofessor: Educação Baseada na Construção de Jogos. Anais do XXVI Simpósio Brasileiro de Informática na Educação (SBIE), p. 637-646, 2015. Disponível em: <http://www.brie.org/pub/index.php/sbie/article/view/5330/3693>. Acesso em: 11 jan. 2018.

OliVeirA, F. N.; POZZEBON, E.; FRIGO, L. B. Scribblenauts Unmasked: Avaliação do Jogo Digital e seus Aspectos Educativos. Informática na Educação: teoria \& prática, Porto Alegre, v. 20, n. 2, p. 239-257, 2017. Disponível em: <http://www.seer.ufrgs.br/InfEducTeoriaPratica/article/viewFile/67961/43631>. Acesso em: 12 jan. 2018.

PANTALEÃO, E.; AMARAL, L. R.; BRAGA E SILVA, G. Uma abordagem baseada no ambiente Robocode para ensino de programação no Ensino Médio. Brazilian Journal of Computers in Education (Revista Brasileira de Informática na Educação - RBIE), v. 25, n. 03, p. 95-111, 2017. Disponível em: < http://www.brie.org/pub/index.php/rbie/article/view/6452/5536>. Acesso em: 12 jan. 2018.

PAPERT, S. Mindstorms: children, computers, and powerful ideas. Da Capo Press. 1993.

PIETRUCHINSKI, M. H.; COELHO NETO, J.; MALUCELLI, A.; REINEHR, S. Os jogos educativos no contexto do SBIE: uma revisão sistemática de Literatura. Anais do XXII Simpósio Brasileiro de Informática na Educação (SBIE), p. 476-485, 2011. Disponível em: <http://www.brie.org/pub/index.php/sbie/article/view/1614/1379>. Acesso em: 13 jan. 2018.

REIS, F.; DAMASCENO, R.; SILVA, F.; RIBEIRO, M. Jogo educativo sobre a Revolução da Cabanagem - Fase Pré-Revolucionária. Anais do XIV Workshop de Informática na Escola (WIE), p. 156-165, 2008. Disponível em: <http://www.br-ie.org/pub/index.php/wie/article/view/973/959>. Acesso em: 13 jan. 2018.

SANTANA, K. C.; PEReirA, C. P.; FERnANDES, A. L. B.; SANTOS, A. J. O. S.; MACÊDO, R. S. Blinds, Basic Education: jogo digital inclusivo para auxiliar o processo de ensino-aprendizagem das pessoas com deficiência visual. Anais do XXVIII Simpósio Brasileiro de Informática na Educação (SBIE), p. 877-886, 2017. Disponível em: <http://www.br-ie.org/pub/index.php/sbie/article/view/7616/5412>. Acesso em: 12 jan. 2018. 
SANTOS, C. P.; BOURSCHEIDT, V. R. R. AdapterGame e suas Contribuições na Concepção de Jogos Educacionais. (2014). Anais do XX Workshop de Informática na Escola (WIE), p. 26-35, 2014. Disponível em: < http://www.br-ie.org/pub/index.php/wie/article/view/3080/2588>. Acesso em: 11 jan. 2018.

SANTOS, J. M. O.; SANTOS, D. A.; GOMES, A. S. M. Brincando e aprendendo: uma proposta lúdica de inclusão social e digital para pacientes de serviços de Oncologia Pediátrica. Anais do XXIII Workshop de Informática na Escola (WIE), p. 1212-1216, 2016. Disponível em: <http://www.brie.org/pub/index.php/wie/article/view/6635/4546>. Acesso em: 12 jan. 2018.

SANTOS, J. S.; COSTA, R. A.; SOUZA, R. P.; PEREIRA, I. B.; PEREIRA, R. S. O. Proposta de um Jogo Educacional para alfabetização de crianças com dislexia. Anais do XX Workshop de Informática na Escola (WIE), p. 457-466, 2014. Disponível em: <http://www.brie.org/pub/index.php/wie/article/view/3129/2637>. Acesso em: 12 jan. 2018.

SARINHO, V. T. LibrasZap - An Instant Messaging Game for Knowledge Assessment in Brazilian Sign Language (LibrasZap - Um Jogo Baseado em Mensagens Instantâneas para Avaliação de Conhecimentos na Língua Brasileira de Sinais). Brazilian Journal of Computers in Education (Revista Brasileira de Informática na Educação - RBIE), v. 25, n. 01, p. 44-59, 2017. Disponível em: <http://www.brie.org/pub/index.php/rbie/article/view/6473/4988>. Acesso em: 11 jan. 2018.

SHIMOHARA, C.; SOBREIRA, E. S. R. Criando Jogos Digitais para a aprendizagem de matemática no ensino fundamental I. Anais do XXI Workshop de Informática na Escola (WIE), p. 72-81, 2015. Disponível em: <http://www.br-ie.org/pub/index.php/wie/article/view/4994/3404>. Acesso em: 12 jan. 2018.

SHIMOHARA, C.; SOBREIRA, E. S. R.; ITO, O. Potencializando a programação de jogos digitais de matemática através do Scratch e da avaliação Game Flow. Anais do XXII Workshop de Informática na Escola (WIE), p. 436-445, 2016. Disponível em: <http://www.br-ie.org/pub/index.php/wie/article/view/6850/4728>. Acesso em: 12 jan. 2018.

SILVA, L. M.; MOURA, R. W. S. O jogo e a aprendizagem significativa. In: III Encontro de Iniciação à Docência da UEPB, 2013, Campina Grande. Revista ENID UEPB. Campina Grande: Editora Realize, v. 1, 2013. Disponível em: <http://www.editorarealize.com.br/revistas/eniduepb/trabalhos/Modalidade_6datahora_04_10_2013_21_1 1_00_idinscrito_712_7ba5f641f9c6e5584dac047223d8fc3c.pdf >. Acesso em: 11 jan. 2018.

SILVA, L. R.; CARVALHO, D. B. F. Saberes D’Avó: Uma Abordagem para o Ensino de Programação no Ensino Médio. Anais do XXII Workshop de Informática na Escola (WIE), p. 1-10, 2016. Disponível em: <http://www.br-ie.org/pub/index.php/wie/article/view/6597/4508>. Acesso em: 12 jan. 2018.

SOARES, I. O.; CASTRO, J. B. Tetris: a geometria em jogo. Anais do XXIII Workshop de Informática na Escola (WIE), p. 480-489, 2017. Disponível em: <http://www.brie.org/pub/index.php/wie/article/view/7266/5064>. Acesso em: 12 jan. 2018.

SUZUKI, N.; CASTELI, T. Ciclo do Trabalho Escravo Contemporâneo. 3. ed. Equipe Escravo, nem pensar!: Natália Suzuki (coordenadora), Thiago Casteli (coordenador assistente) | Projeto gráfco: Marcela Weigert. 2017. Disponível em: <http://escravonempensar.org.br/wp-content/uploads/2017/04/fasc-ciclo-dotrabalho-escravo_web.pdf>. Acesso em: 13 jan. 2018.

TEIXEIRA, R. F.; OLIVEIRA, G. P.; GUIMARÃES, L. C.; ARAÚJO, T. S.; RIBEIRO FILHO, M. Jogo Educativo com Tema Histórico: Fundação da Cidade de Marabá-PA, e o Ciclo Econômico do Caucho. Anais do XXII Workshop de Informática na Escola (WIE), p. 61-70, 2016. Disponível em: <http://www.brie.org/pub/index.php/wie/article/view/6603/4514>. Acesso em: 11 jan. 2018.

VICTAL, E. R. N.; PEREIRA JUNIOR, H. A.; RIOS, P. T. G.; MENEZES, C. S. Aprendendo sobre o uso de Jogos Digitais na Educação. Anais do XXI Workshop de Informática na Escola (WIE), p. 444-453, 2015. Disponível em: <http://www.br-ie.org/pub/index.php/wie/article/view/5072/3477>. Acesso em: 12 jan. 2018.

XAVIER, G. R., et al. Jogo Digital Educativo "Escravo, Nem Pensar!". Relatório. Campina Grande: ETER, 2014. 
Recebido em janeiro de 2018

Aprovado para publicação em julho de 2018

\section{Janderson Jason Barbosa Aguiar}

Programa de Pós-Graduação em Ciência da Computação - Universidade Federal de Campina Grande - UFCG, Brasil, janderson@copin.ufcg.edu.br 